COMMENTARY

Volume 12 Issue 32020

DOI: $10.21315 /$ eimj2020.12.3.6

ARTICLE INFO

Submitted: 07-04-2020

Accepted: 08-06-2020

Online: $30-09-2020$

\section{Social Media Usage among University Students during Exams: Distraction or Academic Support?}

\author{
Camille Le Gall' ${ }^{1}$ Isabelle Le Gall², Alireza Jalali \\ ${ }^{1}$ Faculty of Social Sciences, University of Ottawa, Ottawa, CANADA \\ ${ }^{2}$ Faculty of Science, University of Ottawa, Ottawa, CANADA \\ ${ }^{3}$ Faculty of Medicine, University of Ottawa, Ottawa, CANADA
}

To cite this article: Le Gall C, Le Gall I, Jalali A. Social media usage among university students during exams: distraction or academic support? Education in Medicine Journal. 2020;12(3):49-53. https://doi.org/10.21315/eimj2020.12.3.6

To link to this article: https://doi.org/10.21315/eimj2020.12.3.6

\title{
ABSTRACT
}

Social media are known as facilitation methods when it comes to the way students learn in university. The purpose of this study is to identify the nature of social media usage and their influence on stress levels during exams. A survey directed towards students $(n=179)$ was shared on social media, evaluating the use of social media during exams. About $84.8 \%$ of the participants used social media for educational purposes. The social media employed the most for educational purposes were YouTube $(71.5 \%)$ and Facebook $(68.2 \%)$. Generally, the use of these platforms decreased student stress, particularly Skype, which was mostly used for personal communication. This study validates that social media has a great educational potential and is used by the majority of students. Students have similar yet different needs when using technology during exams and their variability should be considered when creating educational initiatives.

Keywords: Social media, Survey, e-learning, Facilitation method

Alireza Jalali, MD, Division of Clinical and Functional Anatomy, Faculty of Medicine, University of Ottawa, Roger Guindon Hall, Ottawa, ON K1H 8M5, Canada | Email: ajalali@uottawa.ca

\section{INTRODUCTION}

Social media is widely used among university students as is way to facilitate their learning. Social media has an influence on cognitive abilities and practices of users. It is beneficial as an easy access tool for peer support and facilitation of learning. As they are entering a new environment, university students use social media for many different reasons such as communicating with new friends and family members, acquiring knowledge, sharing documents and studying PowerPoint presentations $(1,2)$. It is very common for students to use social media such as Facebook, Twitter, Instagram, Skype and Snapchat, to name a few (3). These tools are increasingly used, not only for information, but also as communication and social outlets (1). Although social media possesses benefits for students, there have been concerns that they could be affecting their levels of stress and anxiety $(4,5)$. The purpose of this study is to gain more insight into how students use social media during examination periods in order to reduce their stress levels. 


\section{METHODS}

The survey directed towards students was shared on different Facebook student groups ( $n=179$ [total]; $n=133$ for undergraduate students, $n=46$ for masters students) during the summer of 2019. It evaluated the reason behind the use of social media among students during exams, including Facebook, Twitter, YouTube, blogs, Skype, text messaging, Instagram, Snapchat, Tinder, Spotify and WhatsApp. Participants answered a total of 16 questions which included open-ended questions, multiplechoice questions and Likert scales.

Students indicated the amount of time spent on each social media on average per day, as well as the frequency with which they used them (hourly, daily, biweekly, weekly, never) during exams. Furthermore, the survey included questions on the amount of time spent on each social media during exams on different technologies such as computers, cell phones and tablets. The possible activities surveyed include: facilitation of studying (e.g., study groups), personal health (e.g., recipes, workout videos), communication and networking (e.g., keeping in touch with family and friends), entertainment (e.g., movies, news), artistic activities (e.g., music, photography) and passing time. Participants also indicated their stress levels before and after using the social media.

\section{RESULTS}

The social media platform used the most during exams was YouTube followed by Facebook and text messaging (Table 1). Participants indicated using Facebook, YouTube, text messaging and Instagram on a daily basis during exams while others were used infrequently (Table 1). In the vast majority, $38.1 \%$ of students used social media between two to four hours per day. Cellular phones were the most common method of accessing social media, with the exception of YouTube, Skype and Blogs, for which computers were most frequently used (Figure 1). The time of day at which students reported using these technologies was variable, with $35.4 \%$ using social media at night (8:00 p.m.-6:00 a.m.), $25.4 \%$ in the evening (4:00 p.m.-8:00 p.m.), $22.1 \%$ in the afternoon (12:00 p.m. $-4: 00$ p.m.) and $17.1 \%$ in the morning (6:00 a.m. $-12: 00$ p.m.).

Altogether, $84.8 \%$ of the participants used social media for educational purposes during exams. The students indicated the reason behind the usage of social media. The social media most frequently used for educational purposes were YouTube and Facebook (Table 1), although their main purposes were "respectively communication and networking" and "entertainment" (Figure 2). Facebook had the biggest proportion of students using the tool for "facilitation of studying", followed by YouTube. Tinder presented the most significant proportion of use for "passing time", while Spotify presented a higher use of "artistic activities".

Overall, the use of social media decreased student stress. On a scale of 1 to 7 , one corresponding to "feeling no stress at all" and seven corresponding to "feeling extremely stressed", the average stress level was 4.87 before usage and 3.85 after the usage of the social media. Out of all the social media, those using Spotify (primarily used for artistic activities), presented the lowest stress at an average of 2.7. The main reason behind the use of Instagram by students was to pass time and surprisingly presented the highest level of stress at an average of 4.11 . 
Table 1: Ratio of university students using each social media during exams evaluated during summer of 2019

\begin{tabular}{lccc} 
Tools & $\begin{array}{c}\text { Ratio using } \\
\text { tool, } \boldsymbol{n}(\%)\end{array}$ & $\begin{array}{c}\text { Ratio using tool specific to } \\
\text { education } \boldsymbol{n}(\%)\end{array}$ & $\begin{array}{c}\text { Frequency of tool used } \\
\text { specific to education } \\
\text { (\% respondents) }\end{array}$ \\
\hline Facebook & $140 / 179(78.2)$ & $104 / 179(58.1)$ & Daily (55.0) \\
Twitter & $40 / 179(22.0)$ & $13 / 179(7.3)$ & Infrequent \\
YouTube & $151 / 179(84.4)$ & $108 / 179(60.3)$ & Daily (51.0) \\
Blogs & $37 / 179(21.0)$ & $38 / 179(21.2)$ & Infrequent \\
Skype & $28 / 179(15.6)$ & $10 / 179(5.6)$ & Infrequent \\
Text & $138 / 179(77.1)$ & $38 / 179(21.2)$ & Daily (42.0) \\
messaging & & & Daily (49.0) \\
Instagram & $125 / 179(70.0)$ & $20 / 179(11.1)$ & Infrequent \\
Snapchat & $71 / 179(40.0)$ & $8 / 179(4.5)$ & Infrequent \\
Tinder & $20 / 179(11.2)$ & $0 / 179(0.0)$ & Infrequent \\
Spotify & $98 / 179(54.7)$ & $13 / 179(7.3)$ & Infrequent \\
WhatsApp & $102 / 179(57.0)$ & $37 / 179(20.7)$ & \\
\hline
\end{tabular}

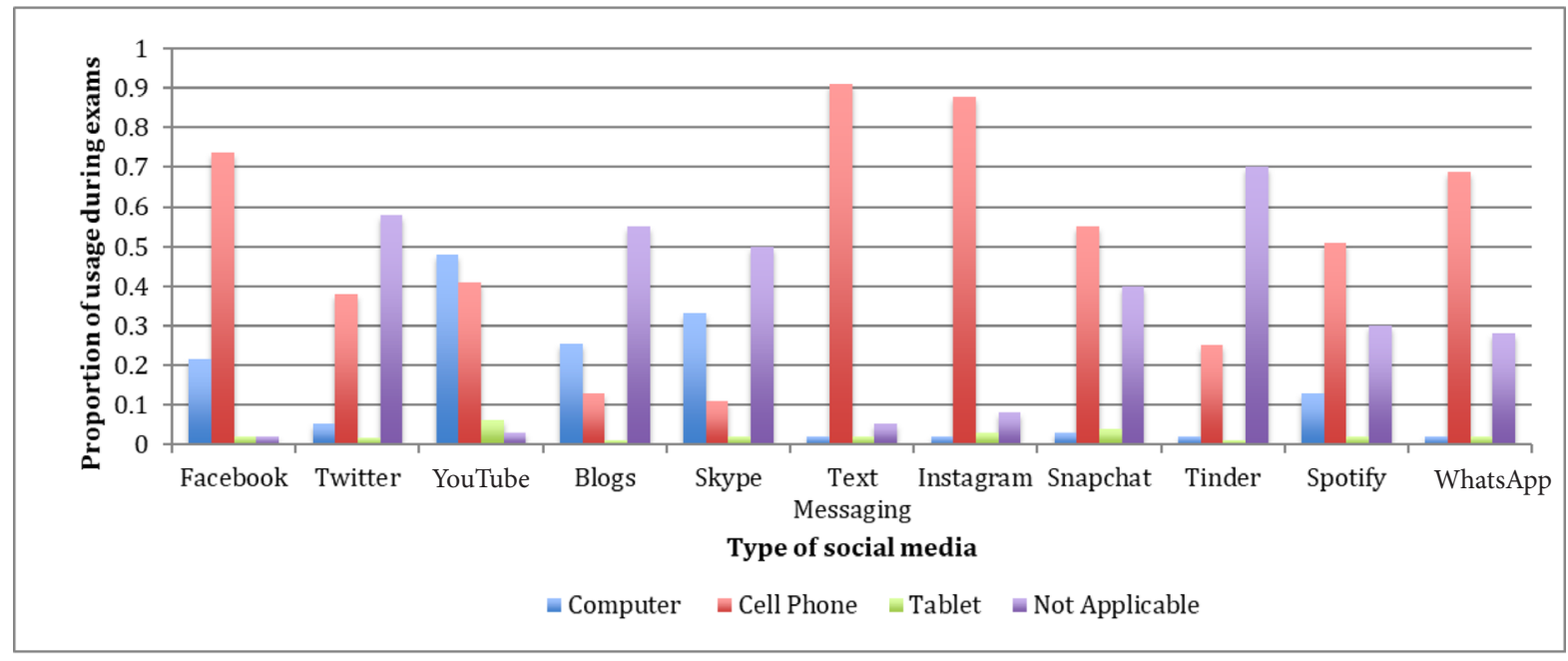

Figure 1: Proportion of social media used on electronic devices for student daily activities during exams. 


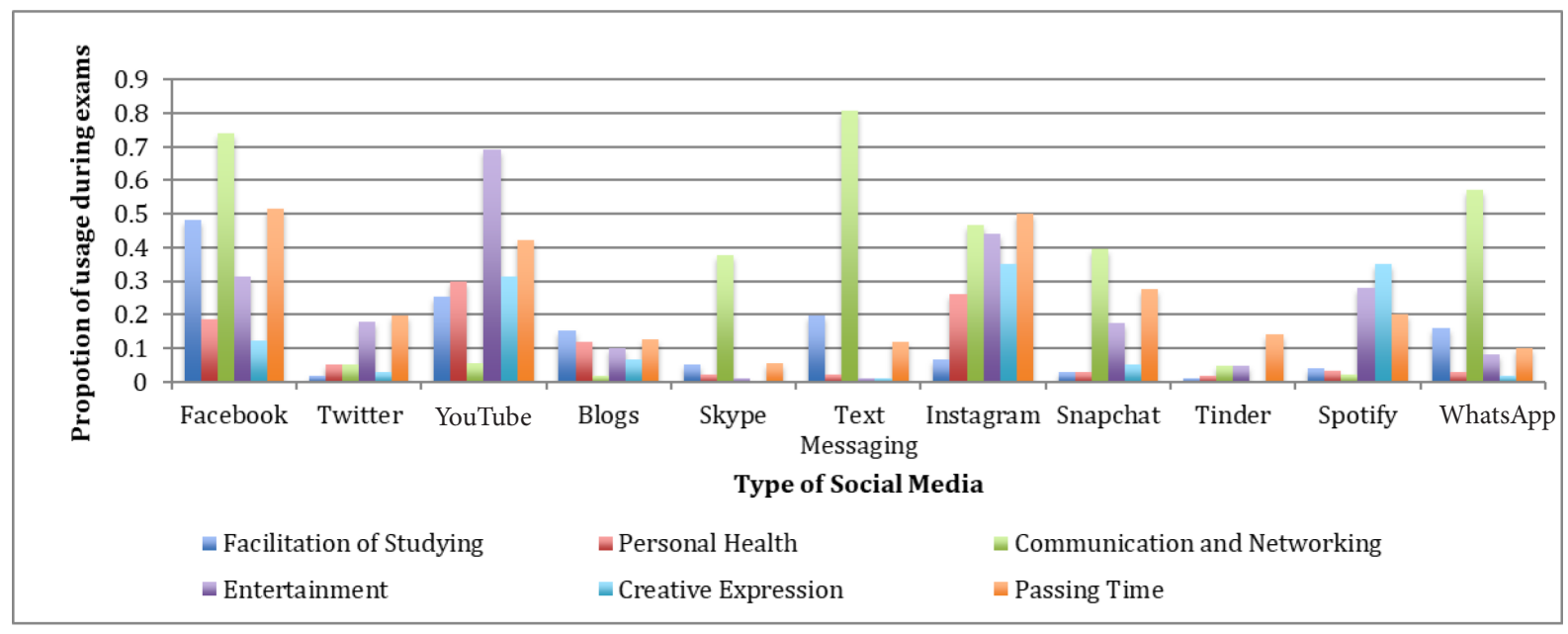

Figure 2: Proportion of students using social media for daily activities during exams.

\section{DISCUSSION}

Social media is widely used by university students for both academic and recreational purposes. Social networks have an influence on cognitive abilities and practices of users. They are beneficial as an easy access tool for peer support and facilitation of learning. Of the academic uses of social media, the most important one is using social media networks as an online structure to facilitate the student's studies, as well as peer support platforms. Notably, collaborative learning opportunities allow an exchange of knowledge while reducing anxiety (6) in comparison to competitive or individualistic effort.

Social media reduced stress during exams. Artistic activities used with tools such as Spotify are known to reduce psychological and physiological stress and anxiety (7). While the primary function of Instagram was "passing time" and students indicated lower stress after using it, the stress level was the most elevated out of all social networks. Negative body image, elevated fear of not partaking in social events and poor sleep hygiene are some results of the use of Instagram obtained by the survey (8).

YouTube and Facebook are mostly for "passing time", as well as for "facilitation of learning", which were a priority for students during exams. Knowing students spend much time reviewing notes and materials from different classes, it is also important to note that the reason for social networking during exams is primarily academic. The exams involve an abundant amount of knowledge meant to learn and share. Besides that, it is the students' main priority during that period.

Although social networks have their assets, there are limitations to consider, such as privacy and distraction. Studies with a greater range of participants concerning the impact of social media on student mental health while studying should be conducted to optimise academic performances while promoting well-being.

\section{CONCLUSION}

Social media has a great potential in both education and stress management. It is used by the majority of students in various manners. Every student wants the same outcome during exam season, that is, to reduce stress. However, the technology approach was different according to student preferences. Therefore, each of their needs should be considered when creating helpful educational initiatives. 


\section{REFERENCES}

1. Mihailidis P. The civic-social media disconnect: exploring perceptions of social media for engagement in the daily life of college students. Inf Commun Soc. 2014;17(9):1059-71. https://doi.org/10.1080 /1369118X.2013.877054

2. Bal E, Bicen H. The purpose of students' social media use and determining their perspectives on education. Procedia Comput Sci. 2017;120:177-81. https://doi. org/10.1016/j.procs.2017.11.226

3. Statista [Internet]. Top U.S. mobile social apps by users 2019; c2019-2020 [cited 22 August 2020]. Available from: https://www. statista.com/statistics/248074/most-popularus-social-networking-apps-ranked-byaudience/

4. Utas Akahn L, Kurtuncu M. Impact of university students' use of social media on their level of loneliness and anxiety. Arch Dis Child. 2014;99 (Suppl2):A538-9. https://doi.org/10.1136/ archdischild-2014-307384.1502
5. Aydogan D, Buyukyilmaz O. The effect of social media usage on students' stress and anxiety: a research in Karabuk University Faculty of Business. IJMT. 2017;6(1):25360.

6. Marjan L, Ghodsi SM. Benefits of collaborative learning. Procedia Soc Behav Sci. 2012;31:486-90. https://doi. org/10.1016/j.sbspro.2011.12.091

7. Stuckey HL, Nobel J. The connection between art, healing, and public health: a review of current literature. Am J Public Health. 2010;100(2):254-63. https://doi. org/10.2105/AJPH.2008.156497

8. Blair O. Instagram ranked worst for young people's mental health, report finds. Independent. 2017 May 19. 